\section{A NEW HISTORY OF CHEMISTRY} A History of Chemistry

Vol. 2. By Prof. J. R. Partington. Pp. xxiv +795 , with 38 illustrations. (London: Macmillan and Co., Ltd. ; New York: St. Martin's Press, Inc., 1961.) 105s. net.

THE appearance of a comprehensive and detailed history of chemistry by Prof. Partington must be hailed as a momentous event in this important field of humanistic science. The author's reputation as an outstanding authority has been long established by his Short History of Chemistry and a legion of specialized papers ranging over many aspects of a vast subject. The Short History of 1937 , reaching a fifth issue in 1960, is universally acknowledged as a masterpiece of accuracy and selective presentation; and this work has now become the harbinger of a massive and fully-documented treatment. Since the classical books of Hoefer and Kopp, dating back to the 1840's, there have been other histories of chemistry, but in general these carry no detailed references to original sources. Moreover, both the science of chemistry and research in historical chemistry have made enormous advances in recent times.

The work is to be issued in four volumes, of which the first to appear (Volume 2) traverses the period 1500-1700, marking the slow extinction of alchemy and the gradual opening of the road leading on to modern chemistry, through the era of phlogiston. Volume 3, 1700-1800, already in the press, deals with the progress of chemistry in France, Scandinavia, Germany, Great Britain and Ireland, passing through the later years of the phlogiston theory to Higgins and Dalton. Volumes 1 and 4, both in preparation, will be concerned with the earliest (to 1500) and latest (from 1800) periods.

To his formidable task the author brings the fruits of extensive reading and research. A work of this scope, marked by sound scholarship, meticulous documentation, accuracy of detail, and copious quotations from original sources, would normally call for the united efforts of a team of specialists; it is therefore amazing to find a single author producing a massive work of this character.

Space allows of the mention of only a few specific points, taken in illustration from the twenty chapters. Essentially, the treatment is based on a biographical plan, lending significance to the humanistic aspect of the subject. Chapter 1 ("Empirical Prelude") leads off with the versatile Leonardo da Vinci, followed by Eck of Sulzbach, Cardan and Porta, with sections on books of poisons and books of secrets. Of Cardan, it is related that he lost a fortune at chess, sold his wife's jewels, and acquired a great reputation by travelling in 1552 from Milan to St. Andrews and curing Archbishop John Hamilton, to the great envy of the Scottish practitioners. Chapter 2 ("Technological Treatises") tells us that Biringuccio, whose Pirotechnia appeared in 1540, had an extensive knowledge of metallurgy and technology, including "such politically useful branches as gun casting, the manufacture of gunpowder, and making false coin". Here, as in general throughout the volume, there is a summary of the bibliography of the author's important writings; a note on his life and career; a full documentation of leading statements; and also quotations in the original language and in English.

A detailed bibliography relating to Paracelsus (Chapter 3) illustrates the great attention that has been devoted to this vivid and blustering man, not least in modern times. Among his iatrochemical successors (Chapter 4) comes Thurneisser, a character little less picturesque than Paracelsus himself. Son of a Basel goldsmith, "in consequence of having sold a gilded brick to some Jews, he left for England in 1548 ," at the age of seventeen; travelling extensively, he developed into a charlatan and business man, resembling Paracelsus in "Geist und Betriebsamkeit". In this chapter it is pleasing to find mention of Mylius and Stolcius, two of many intriguing alchemical figures whom historians of chemistry have generally ignored.

"Basil Valentine" (Chapter 5) is described as, after Geber, "the literary forgery which has misled and perplexed chemists for the longest period". Dealing later with Francis Bacon and others, the author considers the development of philosophical thought in the supersession of the views of Aristotle, with their medieval accretions, by the now ideas of Bacon, Descartes and Gassendi, stressing thereby the importance of including a concise account of philosophical systems which have influenced chemistry.

Judging from the quality of the initial volume, there can be no doubt that this erudite and authoritative work will stand out as a landmark in the literature of historical chemistry.

JOHN READ

\section{SURVIVAL AND SEXUAL SELECTION}

Theory of Sexual Selection

By L. S. Davitasvili. In Russian. Pp. 538. (Moskva: Akademia Nauk S.S.S.R., 1961.) n.p.

CINCE "very many biologists who work on the $S$ evolutionary problem reject the theory of sexual selection, or merely ignore it", the author has set himself the task of collecting carefully any facts which might serve to support the theory as originally formulated by Charles Darwin. Darwin's term "secondary sexual characters", as well as that of J. Huxley, epigamic characters, are considered too broad, and he proposes a category of perigamic characters defined as "such traits of the structure and behaviour of animals which arise and develop through sexual selection". A chapter is devoted to criticisms of other writers on the subject-largely Russianthough the views of Pycraft and J. Huxley are also discussed, not very favourably. In formulating the basis of his own approach to the problem, the author admits that "of course, nobody saw how species are transformed under the influence of sexual selection", but he considers it legitimate to regard as highly' probable such influence in the cases when certain unusual structures cannot be explained by the requirements for obtaining food, movement or defence from enemies.

Fourteen chapters are devoted to a review of the supposed perigamic characters in a number of animal groups, with particular emphasis on the extinct vertebrates-the author being a palæontologist. Recent cephalopod molluses, with their highly developed nervous system, colour changes of males and their fights during mating period are regarded as undoubtedly offering examples of sexual selection; more daringly, perigamic importance is postulated for the external protuberances and, especially, the ligulæ of Ammonoidea. The importance of sexual selection in the living Arthropoda (Crustacea and insects) is regarded as beyond doubt and, therefore, 